ARCHIVO ESPAÑOL DE ARTE, LXXIX, 315

JULIO-SEPTIEMBRE, pp. 243-261, 2006

ISSN: 0004-0428

\title{
TODA LA OBRA CONSERVADA EN ESPAÑA Y HASTA AHORA CONOCIDA, DEL PINTOR SEGISMUNDO LAIRE. ALEMÁN EN ROMA
}

\author{
POR \\ GERMÁN RAMALLO ASENSIO \\ Universidad de Murcia
}

Se estudia la obra conservada en España del pintor alemán Segismundo Leire, completando estudios anteriores del autor sobre este pintor, con la aportación y análisis de nuevos cuadros y revisando antiguas atribuciones.

Palabras clave: Pintura; S. XVI; S.XVII; España; Alemania; Segismundo Laire.

The author, completing his previous studies of the German painter Segismundo Laire, presents the artist's works preserved in Spain, adding and analyzing new paintings and revising old attributions.

Key words: Painting; 16th century; 17th century; Spain; Germany; Segismundo Laire.

El pintor y miniaturista Sigismundo Laire es uno de esos artistas a los que, tras obtener un notable éxito en vida, se les fue olvidando con el paso del tiempo, hasta quedar reducido a unas reseñas en los diccionarios, más completas y laudatorias, según retrocedamos en el tiempo ${ }^{1}$.

Nacido en Munich, en 1552, llegaría a Roma durante el pontificado de Gregorio XIII (1572-85) y allí desarrollaría toda su carrera, siendo reconocido por los mejores pintores del momento lo que le llevó a ser miembro de la Academia de San Lucas (1593) e ingresar en la congregación de Virtuosi al Panteón (1600). Su mucha fama y aprecio coetáneo también se dejó notar en el momento de su muerte, acaecida en 1639 y teniendo por tanto el pintor una edad avanzada. Entonces se

1 Al ser un extranjero en Roma su apellido y su nombre fue transcrito de varias formas. Quizás lo más adecuado sería nombrarle como se hace en el Thieme Becker, Vol. XXII, p. 233: Sigmund Lair, pero habida cuenta de que en este mismo lugar se reconocen los apellidos Laier y Laire, así como la latinización de su nombre: Gismondo y como apellido su topónimo: Tedesco, será prefesible considerar y aceptar todas las posibilidades encontradas hasta ahora. Esto es: Laerer, Laijer, Laier, Laiar, Lyrer (en el ágata de la Encarnación), Sigismondo Leirer (testamento), Sigmund Lair, Gismondo Tudesco o Segismundo Tudesco. A. Vannugli, "Sigismondo Laire. Note documentaire su un "nome senza opere" nella Roma del seicento", Studi Romani, XXXIII, 1985, n 1-2, pp. 11 a 25. 
le hicieron unas honrosas exequias fúnebres, en las que participaron los más importantes profesores de dibujo que terminaron con su entierro en la Rotonda dalle Fratelli della Compagnia de Virtuosi.

Todos estos datos los conocemos por Baglione ${ }^{2}$ que habla de él en términos muy laudatorios y nos informa del aprecio en que se le tenía, de la clientela, formada por las mas nobles familias, así como de su relación con los jesuitas, e igualmente, del rango social que llegó a alcanzar. Lo hace gran especialista en temas de la Virgen y más en concreto en la representación de las tres importantes devociones romanas: Santa María Mayor, Santa María del Pópolo y Santa María de la Paz. También fue recogido el artista y con idéntico tono laudatorio ya que beben de la primera fuente, en los diccionarios de Bénézit, T. III, p. 16 y Thieme Becker, T. XXII, p. 233.

Su primera formación debió producirse en su ciudad natal y esto le permitiría absorber la estética minuciosa y detallista, aunque con tintes fantásticos que imperaba en aquel sur de los territorios germánicos y austriacos para la segunda mitad del siglo y que había impuesto desde principios del siglo XVI la conocida como Escuela del Danubio y luego continuado por pintores manieristas flamencos e italianos de las cortes de Maximiliano II y Rodolfo II. Son deudores de este panorama artístico los paisajes que vemos como fondo de alguna de sus obras, cerrados por altas y azuladas montañas agrestes y salpicados de grandes robles y coníferas; a veces se pueblan de pequeñas arquitecturas fantásticas colocadas en la lejanía, como podemos contemplar en el Apostolado del Museo de Bellas Artes de Asturias (Fig. 1) o en los Santos Penitentes del armario del Monasterio del Sacramento (Fig. 2). Asimismo la utilización de grabados como fuente de inspiración que se puede comprobar en algunos de los cobres incrustados en los muebles del monasterio del Sacramento, de Madrid, habla de un artista acostumbrado a este vehículo de expresión que, por tanto lo usaba con toda libertad y franqueza. E igualmente vemos la influencia de los imponentes grabados de Durero o, antes que él de Schongauer, en la monumentalidad de sus figuras, aunque luego estén sometidas a un proceso de idealización que les afecta principalmente a los rostros. También de esa misma formación centroeuropea, enriquecida con las últimas propuestas flamencas, deben proceder los tonos de color brillantes e intensos, bien definidos en áreas locales y muchas veces, bien contrastados con sus contrarios, como resabio de la estética manierista que había prendido, tarde pero fuerte, en aquellas zonas geográficas. En este mundo norte europeo con quien más paralelismos encontramos, tanto en el uso del color, como en detalles concretos, es con el último periodo de Pieter Aertsen (†1575), así como en lo tocante a los tipos humanos, con Martín Van Heemskerk que pintó por las mismas fechas que el antedicho.

Documentado por su biógrafo está su aprendizaje directo con Francesco da Castello (15561636), pintor flamenco de ascendencia española que también practicó la miniatura y llegó a ser bastante reconocido en su tiempo ${ }^{3}$. Llegó a Roma por los mismos años que Laire, esto es, bajo el pontificado de Gregorio XIII, allí se casó con una romana y vivió hasta su muerte, ocurrida a muy avanzada edad. A esta primera formación se añadiría lo visto en Roma, tanto el inmediato pasado, como las ya pasadas propuestas de Cristofano Roncalli, Il Pomarancio, o Giuseppe Cesari, más conocido como Caballero de Arpino, así como también pudo empaparse de las más novedosas que ensayaban Guido Reni o Annibale Carracci; de hecho se nota una evolución desde la primera obra fechada que conocemos, 1593, el pequeño relicario de La Encarnación de Madrid y las realizadas ya en el siglo XVII, como lo son los cobres del Monasterio del Sacramento, fechados en 1604 y 1607. En la primera, sigue dominando su formación centro y norte europea, sus figuras tienen menos corporeidad y menos clasicismo, sin embargo en las segundas aparecen tratamientos de

\footnotetext{
${ }^{2}$ G. Baglione, Le Vite de 'pittori, scultori e architettti, Roma, 1642, p. 353-54.

3 Bryan's dictionary of Painters and Engravers, London G. Bell and sons, L.T.D., T. I. p, 267.
} 
personajes a escalas monumentales dentro de la pequeñez del formato, un marcado sentido del volumen y una clara definición del movimiento que concreta la acción que quedan cercanos a lo que se veía en las últimas pinturas del Caballero, protegido papal y por ello, figura relevante y a imitar en la ciudad Eterna en esos años del cambio de siglo.

Este artista viene siendo objeto de nuestro interés desde el año 1973 en que presenté una comunicación en el Congreso Internacional, celebrado en Granada, dando a conocer un importante grupo de obras de su mano, pintadas en láminas de cobre de diferentes tamaños, que se encontraban en el relicario del monasterio del Sacramento, de Madrid, incrustadas en dos muebles de preciosa factura manierista ${ }^{4}$. Si bien, por las limitaciones de extensión que imponía el ámbito en que se daba la noticia, solo se reprodujeron cuatro láminas de las más de veinte de que tratábamos. Será ahora cuando presentemos el resto de las obras que componen ese magnífico conjunto, intentando su análisis más pormenorizado. Poco después, localicé un bello Apostolado en el Museo Arqueológico de Oviedo que, de procedencia desconocida, se exponía anónimo en Sala de Feijoo; está pintado en sus correspondientes doce láminas de cobre de 21 x $15 \mathrm{~cm}$. Tamaño que, curiosamente, coincide con el de otras muchas obras suyas de que aquí haremos referencia ${ }^{5}$. Ese conjunto pasó luego al Museo de Bellas Artes de la misma ciudad, donde se le cambió la enmarcación y fue publicado como monografía dentro de la colección: Obras Selectas, del citado Museo.

El pintor, si hemos de creer a las fuentes coetáneas que se ocuparon de él, realizó mucha obra y por ello, habrá todavía una abundante producción en los conventos y monasterios que no hayan salido a la luz y lo mismo, en los ajuares de antiguas ricas familias que le hubieran encargado piezas con el doble fin de la devoción y el aumento de sus tesoros de joyas y curiosidades. De entre ello, hemos podido localizar últimamente una pequeña obra en la clausura del Monasterio de Santa Ana, de Málaga, que representa a la Virgen con el Niño y San Juanito, pieza muy bella que, pese a no ir firmada, pudimos atribuir con toda seguridad por su total similitud con los cobres del Sacramento $^{6}$.

También se han atribuido recientemente a Laire varios cobres pintados que se conservan en el monasterio de Santa Clara de Medina del Pomar y de entre ellos, no ofrecen dudas estilísticas, tres que representan distintas advocaciones de la Virgen: Uno de Santa María la Mayor, otro de Santa María del Pópolo y un tercero que representa a María velando el sueño del Niño ${ }^{7}$. El resto de los que se le atribuyen: Una Anunciación, una Coronación de María y una Lactatio de San Bernardo, no nos parece que puedan mantenerse como suyos, ya que presentan características estilísticas muy diferentes: composición, volumen de las figuras, color, luz, rasgos faciales, etc., más relacionadas con el clasicismo romano que se estaba volviendo a conseguir para la última década del siglo XVI y que cuajó plenamente en el primer tercio del siguiente; a no ser que su estilo cambiara mucho a partir de ese 1607 que es, por ahora, la fecha más avanzada que tenemos de su obra, pensando sobre todo en que, por su extraordinaria longevidad, aun quedaban al artista más de treinta años de vida.

Otra pieza suelta que ha llegado hasta nuestro conocimiento es una preciosa lámina, también de cobre, custodiada en colección particular madrileña que representa al evangelista San Lucas y

4 G. Ramallo Asensio, "El pintor Segismundo Laire en España", Actas del XXII Congreso Internacional de Historia del Arte. España entre el Mediterráneo y el Atlántico. Granada 1973, T. III, Sección: La pintura en los siglos XVII y XVIII, Universidad de Granada, 1978, pp. 205 a 212.

5 Id. "El Apostolado de Segismundo Laire", Obras Selectas, Mercantil Asturias, S. A., 1992, pp. 1 a 6.

6 Id. "Una obra de Segismundo Laire en las clausuras de Málaga", Boletín de Arte, n”. 22, Departamento de Historia del Arte, Málaga, 2001, pp. 509 a 514.

7 E. Gonzalez Terán, (coord.), El monasterio de Santa Clara de Medina del Pomar. "Fundación y Patronazgo de la Casa de los Velasco", Asociación de amigos de Santa Clara, Burgos, 2004. 
ahora se publica por primera vez (Fig. 3). Es muy posible que perteneciera a un conjunto de cuatro del que se hubiese desglosado por cualquier razón, pero también puede ser una pieza que pintara aislada a petición de algún devoto del Santo que ocuparía su oratorio privado.

Según su principal biógrafo citado, pintó también sobre piedra dura y en este material, concretamente en láminas de ágata ${ }^{8}$, se localizaron dos pequeñas piezas que forman las caras de un Relicario que quiere simular una custodia templete y que ahora se conserva en la clausura del Monasterio de la Encarnación, de Madrid ${ }^{9}$, obras firmadas en Roma y fechadas. Se representa por un lado la Anunciación y por el otro, la Resurrección de Cristo. También usando esta misma base, hemos conocido otra obra interesante que, sin tener la evidencia de la firma, como la anterior, nos parece muy asignable al pintor, representa la Estigmatización de San Francisco (Fig. 4) y se conserva en la parroquia de Santa María de la Estrella, Enciso, La Rioja. Tampoco ha sido reproducida hasta la fecha y por ello la trataremos con detalle en las páginas siguientes.

Y asimismo por el mismo biógrafo sabemos que otra de sus especialidades y también muy alabada y por ello muy repetida, fue la de pintar joyas y piedras preciosas para destacada y adinerada clientela. En este arte nos hace saber Baglione de su máxima habilidad por la cual podía hacer "in spatio, quanto un'unghia del dito piccole, storie di otto, e dieci figurine insieme (...) che la vista ordinaria a discernerle non bastava" y también: "Dipinse per diversi Principi, e Principesse, e molte volte dipingeva in gioie diverse, come Lapislázero, Agate, Smeraldi, Crognole e altre cose..." 10 . Así pues, según se deduce debió pintar en el anverso o reverso de gemas y piedras semipreciosas que luego serían engastadas e incluso, esculpir pequeñas figuritas que fuesen utilizadas para componer escenas. Pero otro aspecto de esta actividad que ahora ya conocemos es el de pintar en una pequeña lámina de marfil, papel o vitela que luego sería incluida en la joya, colgante o prendedor, que a su vez se configuraría como tal a base de la enmarcación en metales preciosos y el añadido de otras gemas y perlas. Ese es el caso de un precioso colgante conservado en el Museo Lázaro Galdiano, de Madrid que incluye una pequeña lámina con el rostro de El Salvador. La joya ya fue publicada por Leticia Arbeteta Mira, aunque sin considerar la pintura y por tanto, sin atribuirla11. Esta es la primera joya que se localiza del pintor y se le atribuye casi con toda seguridad. Su análisis estilístico al considerar los colores usados, así como la factura y expresión del rostro es suficiente para pensar de inmediato en Segismundo Laire como autor ${ }^{12}$. Al ser una imagen de Cristo, destinada a relicario y que ha de cumplir y hacer funciones de joya, utiliza un fondo dorado a la manera de icono y sobre éste,

\footnotetext{
${ }^{8}$ Esta técnica la puso de moda en Italia Sebastiano del Piombo, siendo primero utilizada la pizarra por los contrastes lumínicos que proporcionaba, pero también haciéndolo sobre mármol y otras piedras duras. La utilizó el mismo Tiziano y de él se guarda algún ejemplo en el Museo del Prado (un Ecce Homo y una Dolorosa, pintados para Carlos V y María de Hungría, respectivamente). El uso del ágata pronto se vio como idóneo por la riqueza de colores, luces y perfiles ondulados que proponían sus vetas curvilíneas y concéntricas con las que formar los fondos paisajísticos o celestes. Del tiempo de las de Segismundo Laire podemos también reseñar dos piezas muy bellas, con una Piedad y un San Antonio que, atribuidas a Annibale Carracci, se conservan en los aposentos privados de Felipe II, en el Escorial.

${ }^{9}$ M. T. Ruiz Alcón, "Pintura sobre piedra en el patrimonio Nacional”, Reales Sitios, n 38, Madrid, 1973, pp. 55-56. Estas piezas están firmadas y fechadas aunque la fecha está mal leída ya que no se puede corresponder con el año 1553 que propone la autora (Laire nació en 1552), sino con el de 1593.

10 "En el espacio de la uña de un dedo pequeñas historias de ocho y diez figuras ínfimas (que no les faltaba cosa alguna y formadas con tanta hermosura y limpieza, y con diligencia tan extrema conducidas), que la vista ordinaria no bastaba para discernirlas"... "Pintó para varios príncipes y princesas y muchas veces pintaba en joyas diversas, como lapislázuli, ágatas, esmeraldas, y otras cosas”. G. Baglione, ob. cit., p. 353.

11 L. Arbeteta Mira, El arte de la joyería en la colección Lázaro Galdiano, Caja Segovia, Fundación Lázaro Galdiano, 2003.

12 G. Ramallo Asensio, "Una joya con pintura del miniaturista Segismundo Laire”, en J Rivas Carmona (coord.), Estudios de Platería, 2006, Universidad de Murcia, pp. , (en prensa).
} 


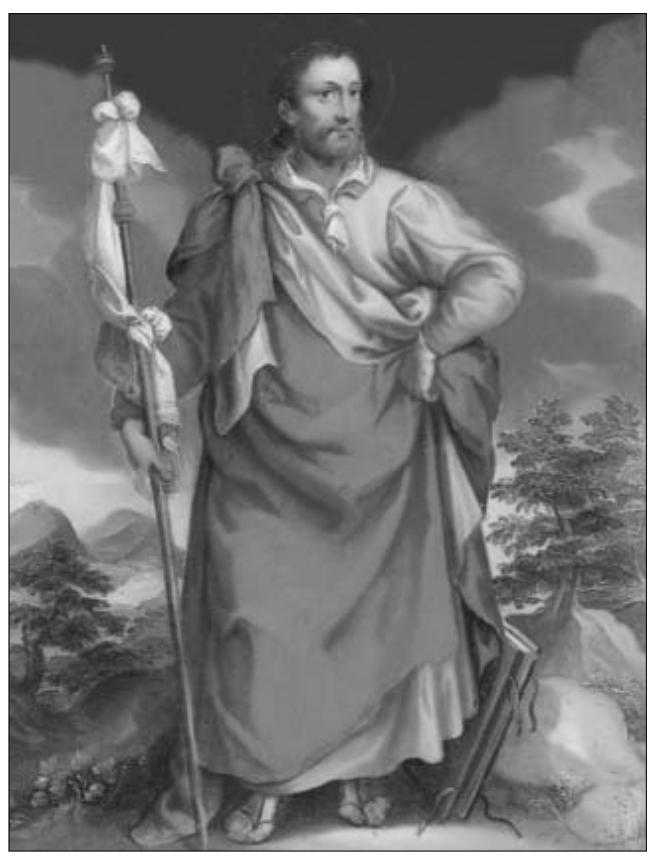

Figura 1. Apóstol Santiago el Mayor.

Perteneciente a un Apostolado. Museo de Bellas Artes de Asturias.

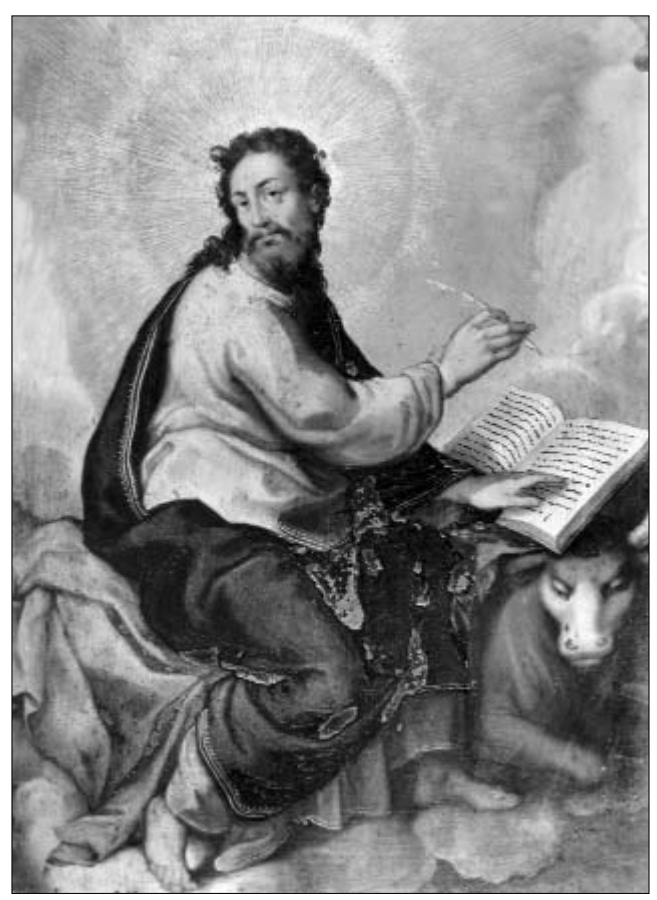

Figura 3. Evangelista San Lucas. Colección particular. Madrid.

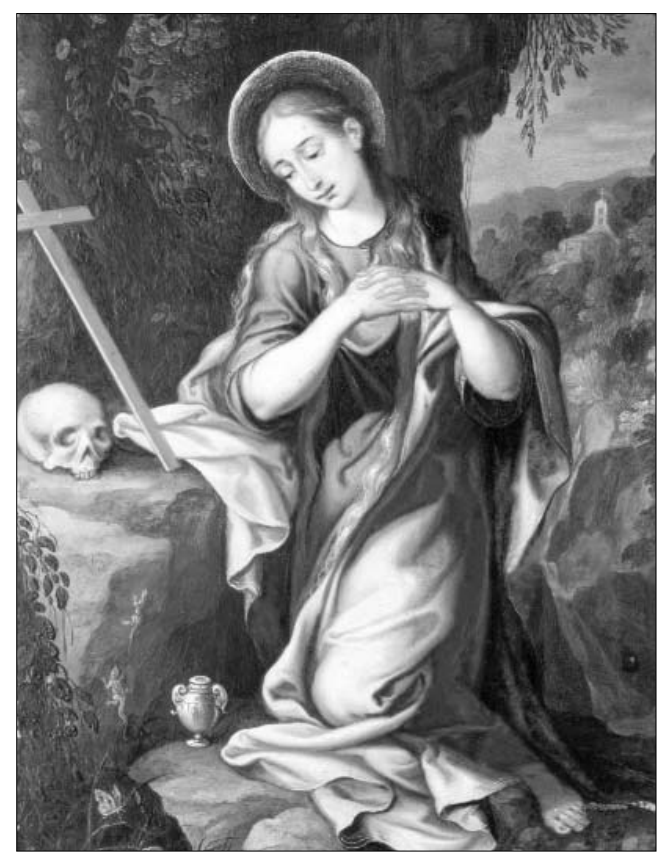

Figura 2. María Magdalena. Cara interior de las puertas del Armario. Monasterio del Sacramento. Boadilla del Monte.

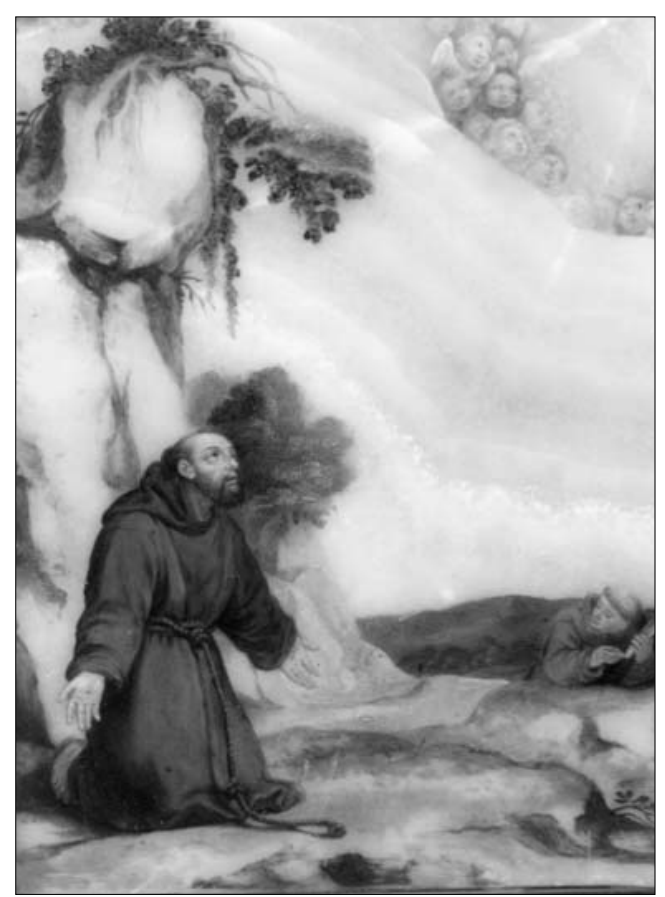

Figura 4. Estigmatización de San Francisco.

Iglesia de Santa María de la Estrella. Enciso. La Rioja.

AEA, LXXIX, 315, JULIO-SEPTIEMBRE, 243-261, 2006, ISSN: 0004-0428 
se recorta delicadamente lo representado. Los rasgos están aún idealizados, incluso más de lo que acostumbra el artista. El rostro es bastante alargado y de nariz recta y también larga, como queriendo acercarse al canon clásico de icono, al igual que hacía con las antedichas presentaciones marianas de iconografía medieval.

Ahora bien, su contacto con la joyería no debió quedar reducido a esto. Es muy posible que él mismo las diseñara, así como lujosos apliques de ricos vestidos a los que también, como veremos en el siguiente punto, podría dotar de pictóricos bordados. A esta conclusión llegamos tras comprobar esa habilidad que Baglione ya destacó, pero asimismo al analizar el atuendo de las Santas Catalina, Inés y Cecilia (Figs. 13, 14 y 15) que protagonizan cinco de las obras conservadas en el Monasterio del Sacramento, de Madrid. En todos los casos las Santas y hasta los ángeles, se visten con lujo de princesas y llevan, además, anchos cinturones metálicos de complicados perfiles, repujados y adornados con piedras preciosas, bordes de escotes recamados de pedrería, y también broches prendedores sujetando los mantos y cerrando los cuellos.

También resulta muy interesante, aunque no extraña, su actividad como bordador, ricamatore, que se le ha documentado de manera indirecta, en el importante artículo de Antonio Vannugli ${ }^{13}$. Es un dato emanado del estudio del inventario hecho sobre la ropa del cardenal Francesco Barberini en el cual se da cuenta de: siete cuadritos de punto de seda de diversos colores hechos por Segismundo para ornamentar una casulla en los cuales se recogían escenas de la vida de San Pedro.

Es curioso que de la abundante obra que debió producir el pintor en su larga vida sólo se hayan encontrado muestras importantes en España. Es cierto que ya anuncia su biógrafo que "en grande no obraba", así como que trabajó mucho para este país y para las Indias, añadiendo que sus clientes principales fueron los jesuitas. Pero nada se ha localizado en Italia, pese a haber muy minuciosos y eruditos investigadores que se han interesado por el artista, como hemos citado en la nota anterior ${ }^{14}$.

Quizás también podríamos precisar que lo conservado en España parece sea debido a regalos hechos por nobles particulares a los monasterios o conventos, siendo consideradas las obras como objetos apreciados y valiosos por el donante, que los traería directamente desde Roma o los adquiriría en las mejores almonedas y testamentarías. Esa sería la procedencia de los dos suntuosos muebles del monasterio del Sacramento en que se insertan sus cobres que fueron regalados por el Duque de Uceda al monasterio en el momento de su fundación, acaecida en $1612^{15}$. Junto al monasterio e incluso, intercomunicado con él por medio de arco elevado, levantó su palacio de claro aire romano ${ }^{16}$. Y asimismo el otro conjunto que ha salido a luz últimamente inserta en relicarios

13 A. Vannugli, "Sigismondo Laire. Note documentaire su un nome senza opere”, Studi Romani, XXXIII, Roma, 1985, pp. 18

${ }^{14}$ Este autor propone la atribución a Segismundo Laire de dos pequeñas pinturas sobre alabastro que se conservan en la Galería Borghese, de Roma. No las he visto directamente y la reproducción no demasiado buena, así como el estar en blanco y negro no permite apreciar los rasgos del rostro, tan personales del pintor y menos aun el uso del color que, por su brillo y matices es también determinante para ajustar la atribución.

15 Para ello contó con doce religiosas venidas desde Santa Ana de Valladolid. El monasterio se comenzó a construir desde ese año citado, aprovechando la situación privilegiada que vivió tras la caída en desgracia de su padre, el Duque de Lerma. Ya el 10 de Enero de 1623 murió la primera religiosa en la casa y el 16 de Julio de 1630 la primara abadesa, la madre María de Jesús, después de haberlo sido catorce años. Estos datos están tomados del Libro de Bóveda y gracias a él sabemos que al menos en 1616 ya estaban las religiosas instaladas en Madrid. Ahora ya no se conserva el inmueble pues las religiosas lo vendieron al Ayuntamiento de Madrid que lo demolió para levantar dependencias municipales (1973) y la iglesia pasó a ser iglesia castrense, conservándose en la actualidad con toda su dotación y en muy buen estado y belleza tras la restauración a que fue sometida.

16 Como se sabe el palacio se conserva en la actualidad, aunque con las remodelaciones del siglo XVIII, está ubicado al final de la Calle Mayor y se conoce como Palacio de los Consejos. Se comenzó a levantar en 1613 y pese a 
y objetos de devoción regalada también al monasterio: Santa Clara del Pomar y por personaje de noble alcurnia, como lo era el Sr. Don Juan Fernández de Velasco. El regalo está compuesto por varias láminas de cobre, pero las asignables al pintor, las tres que representan a María, están insertas en relicarios y por ello se transforman en objetos de veneración que adjuntan obra de arte, haciéndolos aun más preciosos ${ }^{17}$.

\section{Posible autorretrato}

Ya Vannugli, en el artículo que venimos citando, publica un grabado de Ottavio Leoni en el que se reproducen cuatro cabezas masculinas que llevan anotado el nombre en la parte inferior del grabado, escrito a mano y en fecha posterior al grabado. De entre ellas, en el extremo derecho hay una de perfil con el pelo corto y liso, bigote y perilla en la que pone: Laire. Aporta también otro posible retrato que al menos, ha pasado por tal retrato de Segismundo Laire, durante algún tiempo, obra al óleo que ha estado atribuida a algún desconocido seguidor de Caravaggio. Esta, tras una serie de considerandos y razonamientos queda descartada como tal retrato del artista. Pero, por último quisiéramos proponer un posible autorretrato en el Apostolado del Museo de Bellas Artes de Asturias. En este conjunto, pese a estar todos caracterizados por la edad y por los objetos con que les identifica, tienen un aire de familia y un tinte idealizador que les homogeneiza, sin embargo a Santiago el Mayor (Fig.1) se le tiende a individualizar con un rostro más ancho y una presencia más material y sobre todo, lo que mas llama la atención es la franca mirada que lanza al exterior del cuadro desde su rostro de tres cuartos. Ante esto quizás podríamos pensar en un autorretrato que justificase esa actitud, ajena en todos los demás.

\section{La clientela}

Ya su primer y más explícito biógrafo, el citado Baglione, nos informa de que trabajó para príncipes y princesas, esto es, para la sociedad más destacada de la Roma del momento. Igualmente nos informa de lo que hizo y mucho para los jesuitas y concreta, españoles, que llevarían su obra a las Indias. Esto debemos interpretarlo como pequeños retablitos fácilmente transportables y resistentes a los avatares del viaje que luego serían utilizados en sus oratorios de campaña o como soporte gráfico de sus enseñanzas religiosas: desde luego, sus pinturas respiran una honda espiritualidad y serían muy capaces de mover a la devoción. Pero además de ello debemos subrayar los dos clientes que constatamos en España; uno el Duque de Uceda, hombre importante donde los hubiera y sobre todo, tras la caída en desgracia de su padre, el Duque de Lerma, y el otro, ese Fernández de Velasco, fundador y promotor, otro miembro destacado de las más grandes familias españolas. Y por último anotemos la noticia que proporcionó Vannugli de los cuadros bordados para ropa sacra y destinados al cardenal Francesco Barberini. No cabe duda de que fueron sus clientes los personajes más destacados, tanto en el ámbito religioso, como en el nobiliario y ello sería también lo que le llevó a ser tan altamente considerado y merecedor de una voz en el Tratado de tan exigente biógrafo.

\footnotetext{
haberse sometido a materiales hispanos y aun a haber estado flanqueado por torres, acusa la voluntad de copia romana que debió impulsar a su promotor a la hora de mandar su construcción. Junto a él y algo retrotraída, dando ya por tanto a la Calle del Sacramento, se levanta la iglesia que no se concluyó hasta entrada la década de los 70 .

17 Ver nota $n^{\circ} 7$.
} 


\section{Las obras del monasterio del Sacramento de Madrid ${ }^{18}$}

Estas obras suponen el mayor conjunto hasta ahora registrado del pintor. Cuando las conocimos estaban enmarcadas en dos preciosos muebles de finales del siglo XVI, conservados en la estancia Relicario del monasterio de religiosas cistercienses del Santísimo Sacramento y una de ellas, aislada en marco independiente, si bien del mismo periodo histórico ${ }^{19}$. Los dos muebles tienen una enorme importancia para los estudiosos de estos objetos, aunando un gran valor material y artístico. La madera usada para el revestimiento es el ébano de gran densidad y peso, y oscuro color, aunque en algunas zonas parece también aparecer la caoba muy oscura 20 .

El mayor es un gran armario de $366 \mathrm{~cm}$. de alto por $150 \mathrm{~cm}$. de ancho y 63 de fondo que, en altura, está dividido en tres partes (Fig. 5). La inferior, con basamento moldurado y cornisa está flanqueada por anchas bandas verticales y su frente compuesto de cuatro cajones, dos a dos, acogiendo en todos sus frentes unos delicados candelieri y tarjetas, elaborados en incrustación de hueso y marfil. El cuerpo central apoya directamente sobre el que le sirve de pedestal o basamento, aunque se remata con entablamento completo y frontón curvo; está flanqueado por muy esbeltas pilastras toscanas, ocupando su parte central dos puertas batientes. También esta zona intermedia está toda decorada: las pilastras, friso y frontón con el mismo sistema de candelieri y guirnaldas que vimos en la parte baja y realizados con igual técnica y materiales, añadiendo también unas cabezas de ángel dibujadas en negro sobre marfil en los recuadros del friso, y las hojas batientes, divididas en cuatro registros iguales a base de finas incrustaciones de madera más clara que van dibujando tarjetas concéntricas de perfiles mixtilíneos. El piso superior es un ático terminado en frontón triangular que se completa con jarrones a los lados y bolas en la parte superior, realizados a gajos en que alterna la negra madera y el claro hueso o marfil; en su única calle de forma apaisada, se aloja un cobre con la Ultima Cena, único visible al exterior de entre todos los que decoran el mueble por el interior. Además de todo lo dicho como ornato, aun se enriquece el mueble con el bronce dorado de los capiteles y basas de las pilastras y placas de piedras semipreciosas en el centro de los frontones y frentes del pedestal de los jarrones.

$\mathrm{Al}$ abrirse las dos puertas batientes el espectáculo del interior es fastuoso en color y riqueza y de un gran nivel artístico (Fig. 6). En la cara interna de las puertas se enmarcan con moldura dorada dieciséis láminas de cobre, ocho y ocho, de 21 por $15 \mathrm{~cm}$. cada una y aun así se vuelven

\footnotetext{
18 Hay un breve artículo en el que D. Elías Tormo da noticia de algunos objetos destacables de la clausura del Monasterio y en él habla de los muebles y hasta los reproduce en fotografía, pero no hace más que describirlos y apenas dice otra cosa que no sea que están adornados con los cobres pintados. E. Tormo, "La clausura de las Bernardas del Sacramento", Boletín de la Sociedad Española de Excursiones, año 1921, 2 trimestre, pp. 125 a 129.

19 Fue en el año 1971 y en ese mismo momento se fotografiaron por Manso, fotografías que ahora usamos. Pocos años después las religiosas se trasladaron a un nuevo monasterio en Boadilla del Monte y como lo expuse antes, fue vendido y demolido el anterior (1973), ocupando en la actualidad su solar un inmueble que acoge dependencias del cercano Ayuntamiento. La iglesia pasó a ser iglesia castrense, conservándose en la actualidad con toda su dotación y en muy buen estado y belleza tras la restauración a que fue sometida. Los preciosos objetos que componían el Relicario fueron con ellas y lo mismo los dos muebles que acogen los cobres pintados.

${ }^{20}$ Un mueble parecido en cuanto al enriquecimiento con piedras duras, bronces y pinturas sobre cobre, podemos ver en el Museo del Castello Sforcesco, de Milán, propiedad que fue del canónigo Quintilio Lucini Passalacqua. Simula una fachada de dos pisos, revestida de órdenes clásicos y coronada por balaustrada; en las tres calles se abren puerta y ventanas con frontones que alojan estatuitas de marfil y de bronce —en la puerta central, estas últimas-, debidas a Guglielmo Bartolotti y en los antepechos, cinco minúsculas pinturas que ilustran episodios de la Biblia y son debidas a Pier Francesco Mazzucchelli, Morazzone. C. Alberici, Il móvile lombardo, p. 67. Véase también el amplio repertorio recogido en T. Pignatti, "Mobili Italiani del Rinascimento", en A. Vallardi, Le Arti nella casa italiana, Milano 1961.
} 
a ver los dibujos de incrustaciones con madera clara que aquí se complementan con delgadas láminas de piedra dura. Y en el frente se repite la estructura arquitectónica del exterior, con pilastras toscanas y entablamento completo. Ahora sirve para enmarcar un arco de medio punto que se rehunde en forma de hornacina con bóveda de medio cañón con casetones, formando un, a modo de presbiterio que acoge una estructura arquitectónica toscana, extendida hacia los laterales y compuesta por un cuerpo y tres calles, remontado todo por sotabanco y ático de una sola calle. Aquí se utilizan las piedras duras para las columnas y las láminas de ágata y otras piedras para los frentes de los plintos, basas y enlosado, y el bronce dorado, para los capiteles y basas, frontones partidos de las calles laterales y cabecitas aladas de ángeles, además de otros pequeños detalles, así como para la balaustrada que cierra ese simulado presbiterio. También todo este frente se llena de láminas de cobre pintadas con gran finura y brillantes colores. La arquitectura es sobria, aunque aun de apariencia algo endeble y el uso de los tonos contrastados nos recuerda las últimas obras que se hacían en Roma a finales del siglo XVI, principalmente las de Flaminio Poncio, momento en que, al margen de la fecha apuntada en los cobres de Laire, puede situarse su factura.

Este mueble se complementa con un buen número de cobres pintados. Además del ya citado de la Última Cena del remate y los dieciséis del interior de las puertas, hay setenta y dos pequeños $(4 \times 4 \mathrm{~cm}$.) pintados con cabezas de ángeles y colocados en cada uno de los casetones de la bóveda, además de los ocho de distinto tamaño que ocupan los recuadros del retablito central: la Anunciación y el Crucificado en la calle central, la Visitación y Flagelación en la calle lateral izquierda, y la Adoración de los Pastores y Oración del Huerto en la derecha. Por último, también los hay en los triángulos curvos con que se cierra el cuerpo ático, colocando aquí a San Jerónimo penitente y a San Francisco en oración. Para terminar y como otra muestra del preciosismo que guió al artífice de este precioso armario, dos evangelistas, Lucas y Juan, hechos en bronce dorado ocupan las hornacinas bajas de las calles laterales.

De entre todos los cobres enumerados solamente se ha encontrado firma en tres de ellos y ésta pertenece a Segismundo Laire, indicando el lugar: Roma y en dos de ellos, la fecha. Los firmados son: el Arrepentimiento de San Pedro, sin fecha; Santa Cecilia en Gloria, 1604, y los Desposorios Místicos de Santa Catalina, de 160721. Pero son varios más los que pueden serle atribuidos con toda seguridad y algunos otros con alguna reserva. Los primeros son otros ocho de los que se ubican en la cara interior de las puertas y son estos ${ }^{22}$, en la de la izquierda, Santa Catalina, Santa Cecilia en oración, San Francisco asistido por ángeles y San Juan Bautista con el Cordero. Y en la de la derecha, Magdalena penitente, Santa Ana la Virgen y el Niño, Los desposorios de Santa Inés, y San Miguel venciendo al Diablo. Y los que estando fuera de las puertas, también parecen muy asignables a su estilo son: La Última Cena, del ático del mueble, con dudas (Fig. 20), y el Crucificado y Anunciación de la calle central del retablito simulado en su interior, así como una Oración del Huerto que ocupa el recuadro de su calle lateral derecha. Los primeros, los de las puertas, tienen las dimensiones antedichas: 21 x $15 \mathrm{~cm}$. Algo mayores son la Anunciación $(29$ x $21 \mathrm{~cm}$.) y el Crucificado (27 x 17'5), así como La Última Cena que además es apaisado como el tema requiere $\left(28 \times 36 \mathrm{~cm}\right.$.). Mucho más pequeño es la Oración del huerto $\left(6 \times 8^{\prime} 5 \mathrm{~cm}\right.$.) y por ello en él se aprecian muy bien esas cualidades que tanto le alabaron sus contemporáneos. Así pues, en total y sólo en este mueble, tenemos once asignables directamente a su estilo, con toda

\footnotetext{
21 Estos ya se publicaron en el artículo citado en la nota $\mathrm{n}^{\mathrm{o}} 4$ y por ello a él nos remitimos a fin de no alargar innecesariamente estas páginas.

22 En el anterior artículo en que se informaba de estos muebles y los cobres y se presentaban los cuatro firmados dimos como seguros diez. Añadimos ahora uno más que es el que representa a Santa Ana con la Virgen y el Niño ya que, al analizar los rostros, nos evidencian la misma autoría de Laire.
}

AEA, LXXIX, 315, JULIO-SEPTIEMBRE, 243-261, 2006, ISSN: 0004-0428 
seguridad, tres de ellos, firmados, y además otros cuatro que, pese a mostrar algún detalle dudoso, también le pueden ser atribuidos 23 .

Algo curioso que hemos de señalar es que, pese a lo que se pudiera esperar en los dieciséis cobres de las puertas, no hay unidad narrativa. Se presentan momentos de la infancia de Cristo que incluso están repetidos en el retablito interior. Asimismo la delicada escena de la Virgen de la sopa. Resulta raro también la presencia de sólo dos apóstoles y ni siquiera de los que tradicionalmente se interrelacionan, son estos Pablo y Simón. Ahora bien los firmados o atribuidos a Laire sí presentan una coherencia interna y con el momento devocional que se vivía cuando la composición del armario. Estos representan a los más destacados Santos penitentes, como lo fueron Pedro, María Magdalena y San Juan Bautista, así como a Santas que gozaban de plena popularidad, como Cecilia, Inés y Catalina de Alejandría ${ }^{24}$. De Santa Inés sólo se representa el momento de sus Desposorios místicos, pero las otras quedan ensalzadas en dos momentos: los Desposorios e Imagen Gloriosa, para Santa Catalina, y La Oración Recompensada e Imagen Gloriosa, para la Santa patrona de la música. Los otros cobres son los de Santa Ana Triple, la madre de María que, junto a su esposo terrenal y, algo más tarde San Joaquín, estaban experimentando un proceso de renovación e intensificación del culto, gracias a los jesuitas y otras órdenes modernas o modernizadas. San Francisco de Asís que, tras el desmayo sufrido después de su estigmatización está siendo auxiliado por ángeles, o el valor del misticismo y el desprendimiento. Y por último, el triunfo de San Miguel sobre el Diablo, el Miles Christi o triunfo del bien sobre el pecado, o mejor aún, el catolicismo romano ante las herejías que habían escindido al pueblo cristiano. Todo son advocaciones de la máxima actualidad para esos años del cambio de siglo en que se estaban pintando que no andaría lejos del momento de factura de los muebles, aunque fuesen regalados al monasterio español algún tiempo después.

El segundo mueble es mucho mas complejo de estructura y mide $170 \mathrm{~cm}$. de alto por $150 \mathrm{~cm}$. de ancho y $50 \mathrm{~cm}$. de fondo. Podemos dividirlo en dos zonas claramente. Una inferior muy apaisada con basamento y entablamento, se articula en función de una calle central saliente y configurada como templete formado con columnas toscanas y frontón y otras dos calles laterales extremas, también algo salientes y compuestas de dos pisos: el inferior como arco flanqueado por columnas y el superior con recuadro enmarcado. Entre ellas quedan las entrecalles que se ocupan con seis recuadros enmarcados (Fig. 7). Todo ello es practicable por puertas individualizadas. En realidad esta parte es la más importante ya que el edículo central se concibió como sagrario y de ello hizo la función durante muchos años, hasta que no estuvo concluida la iglesia ${ }^{25}$ e igualmente, los armarios de las calles laterales extremas, así como los de las entrecalles estaban destinados a guardar las auténticas de las reliquias que habían sido entregadas al monasterio. La madera usada también es el ébano con incrustaciones de madera más clara que va formando cadenetas o marcos. Pero además, se añaden las láminas de piedras semipreciosas y los cabujones de cristal de roca, material éste que también se utiliza para los fustes de columnas y balaustres de las barandillas. Las láminas de cobre pintado también se insertan en la superficie: Cristo Salvador (16 x 11

\footnotetext{
${ }^{23}$ Aunque no vamos a entrar en el análisis de los otros cobres alojados en las puertas del mueble pues parecen corresponder a otras varias manos que sí usaron de grabados u otras fuentes de inpiración, sí pasaremos a enumerarlos, exponiendo el tema que recogen. En la puerta de la izquierda, los dos de arriba recogen La Virgen de la sopa (tomada de un cuadro de Hipólito Scarsella, Scarsellino) y la Adoración de los pastores (copia de Jacopo Bassano), S. Pablo (según modelo de Rafael, grabado por Marcantonio Raimondi) y el último de abajo, ángulo derecho, Santa Francisca Romana. En la puerta de la derecha: San Simón (según los modelos de Rafael, grabados por Marcantonio Raimondi).

${ }^{24}$ De Santa Cecilia se había descubierto el cuerpo incorrupto el 28 de Octubre de 1599, momento que había inmortalizado con todo dramatismo la escultura de Estéfano Maderno. Otro tanto pasó con Santa Inés a la que se levantaría grandiosa iglesia en Piazza Navonna.

${ }^{25}$ Información oral de las religiosas al momento de realizar las visitas y fotografías, en 1971.
} 


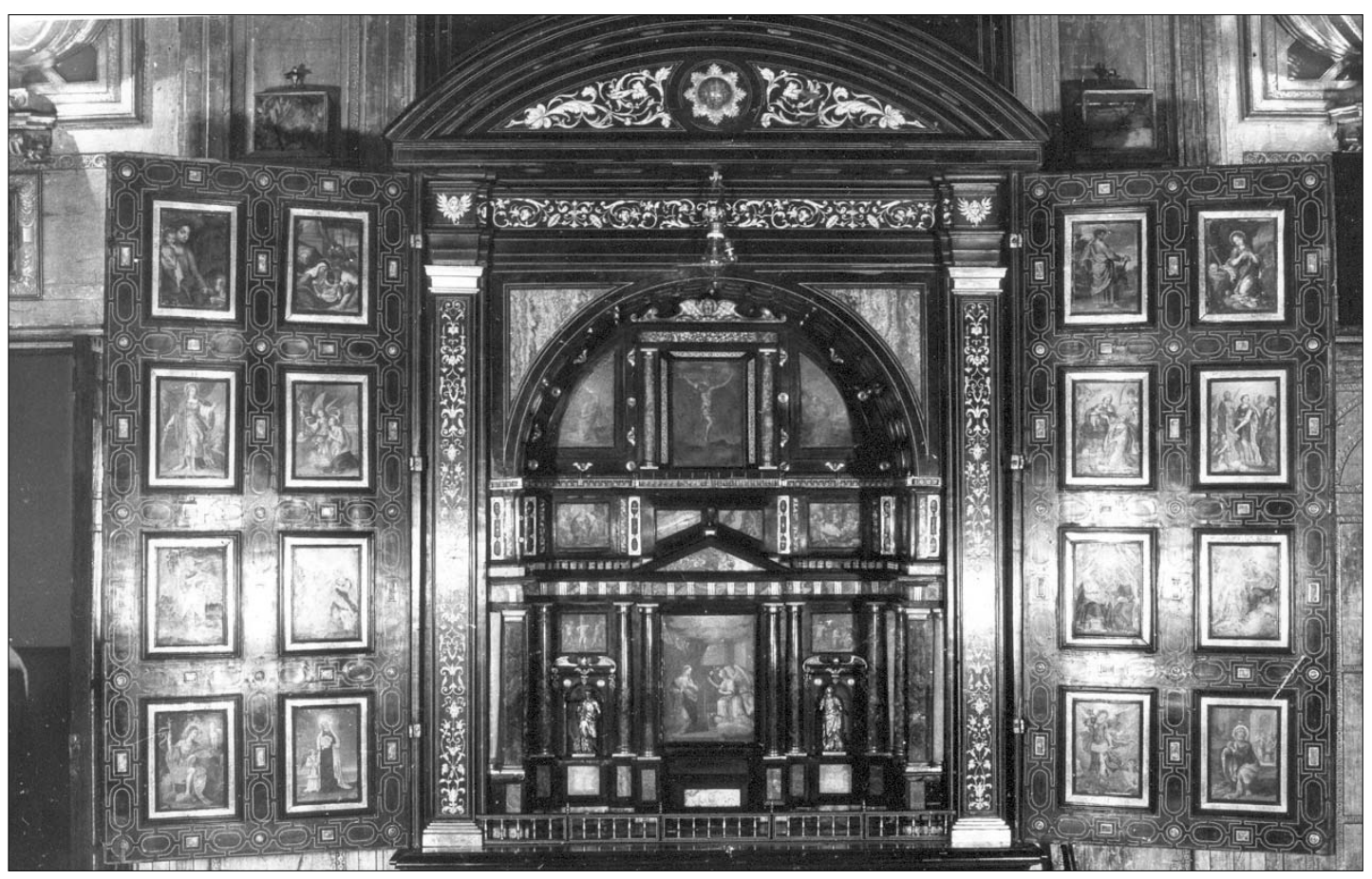

Figura 6. Armario. Detalle del interior. Monasterio del Sacramento. Boadilla del Monte.

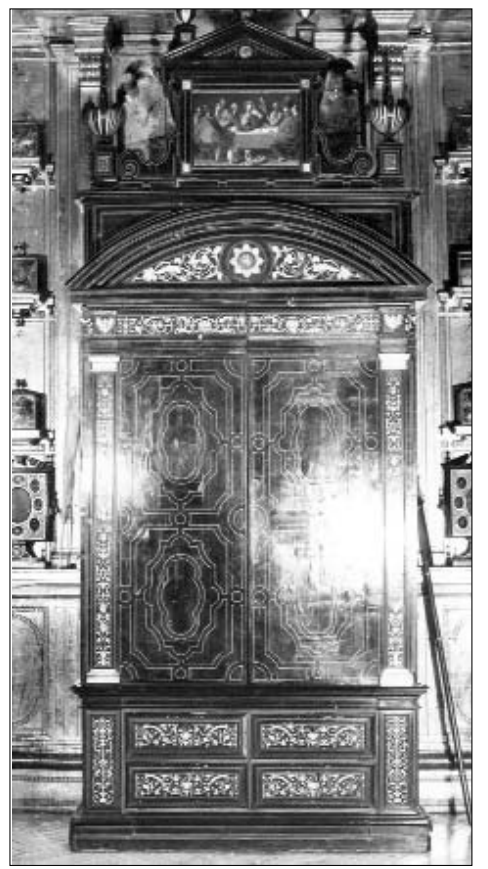

Figura 5. Armario. Vista de

conjunto y cerrado. Monasterio del Sacramento. Boadilla del Monte.

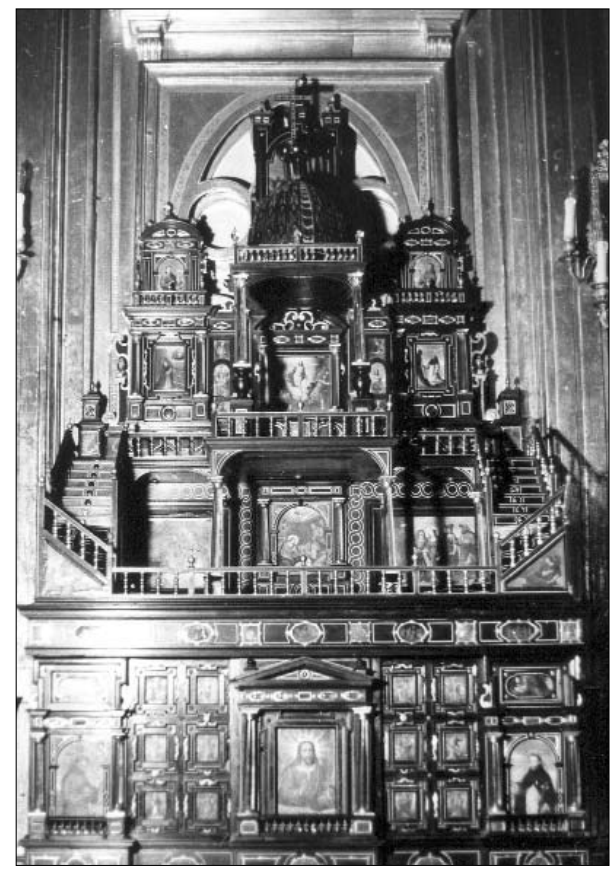

Figura 7. Mueble eucarístico y relicario. Vista de Conjunto. Monasterio del Sacramento. Boadilla del Monte. 
cm.), en la puerta del sagrario, San Francisco y Santo Domingo, en las de las calles laterales extremas, con la Magdalena y otra Penitente, en los recuadros que hay sobre ellos, y un completo Apostolado en los 12 recuadros de las entrecalles (5 x $4 \mathrm{~cm}$., cada uno). A Segismundo Laire se le pueden atribuir con toda seguridad, tanto la lámina central del Salvador, como todos y cada uno de los apóstoles de los pequeños recuadros.

La segunda parte del mueble, o zona alta, no tiene capacidad para guardar, siendo una fantástica construcción, formada por un baldaquino de dos pisos y cúpula, flanqueado por dos calles laterales de tres pisos y unas escalinatas que suben en doble rampa hasta el segundo piso del baldaquino central (Fig. 8). Es, en realidad, un Triunfo realizado con toda la imaginación y riqueza que caracterizaba estas construcciones de carácter efímero. Para formarlo se superponen los órdenes jónico y corintio que, con el toscano inferior, le dan rigor clásico a este capricho arquitectónico. También toda esta parte alta está compuesta de las mismas maderas, bronces dorados en capiteles, basas y barandillas y asimismo, vemos los cabujones y piedras duras por las cenefas y frentes de los plintos, el cristal de roca en columnas y balaustrada superior, y hasta quince láminas de cobre pintadas, de muy distintos tamaños y formatos que están distribuidas por todos los paramentos frontales. En ellas se evidencian distintas manos de autor, aunque en algunas, como la Resurrección y Ascensión hay referencias claras al estilo de Laire. El conjunto se concibió como una apoteosis de la Eucaristía Reservada, máxima y más sagrada reliquia que pudiera tenerse, acompañada por las de otros justos que habían alcanzado ya la Gloria y esto se completaba en la parte superior con la exposición de los más importantes momentos de la vida de Cristo sobre la Tierra; viéndose de abajo a arriba: el Nacimiento, flanqueado por la Anunciación y la Visitación, seguida de la Resurrección y al final, la Ascensión. Este último cobre queda oculto por la cúpula, pero este elemento es desmontable, de tal forma que en día que se celebrase esta festividad, se quitaría, dejando así el hueco de su diámetro y aparecería el cobre de la subida de Cristo al Cielo.

Hemos dicho que, tanto el Salvador de la puerta del Sagrario, como los Doce Apóstoles son totalmente asignables al pintor. Por tanto con ello y los trece cobres que hemos señalado en el mueble anterior (once indudables y dos atribuidos: Anunciación y Crucificado) son veintiséis los que se pueden asignar con toda seguridad a su mano 26 . El Salvador está representado a la manera más convencional: de medio cuerpo y bendiciendo, lleva el Orbe en su mano izquierda (Fig. 9). Su rostro es muy bello y de rasgos idealizados, alargado y de cabellos lacios, muy parecido al que decora la joya que existe en el Museo Lázaro Galdiano.

Pero aun queda otro enmarcado con independencia de los dos muebles, aunque tiene el mismo tamaño que los de las puertas del primero. Representa a la Virgen de los Dolores, o del Séptimo Dolor, en oración y con las siete espadas en el pecho y también está firmado ${ }^{27}$.

\footnotetext{
${ }^{26}$ En el friso del primer cuerpo y en toda la parte superior se cuentan muchos más cobres pintados de muy variados tamaños y también cristales pintados por el reverso. Al no poderse atribuir con total certeza al pintor no los vamos a analizar, pero sí parece conveniente exponer los temas iconográficos que son tratados pues en este mueble notamos una intención narrativa que no se veía en el primero comentado. Ya en el friso y alternando con piedras y cristal de roca, como una joya mas, se recogen cinco cristales pintados con escenas de la infancia de Cristo: Visitación, Nacimiento, Huída a Egipto, Adoración de los Magos y Circuncisión. En los frentes de la escalera: la Justicia y la Fe. Al fondo de este primer piso: Anunciación, Adoración de los pastores y Visitación. En el segundo piso, en el basamento y en tamaño pequeñísimo, como los del friso del cuerpo bajo, escenas de la Pasión pintadas sobre cristal y con el orden que apuntamos: Prendimiento, Última Cena, Oración del Huerto, Jesús ante Herodes, Ascensión y Bautismo. En los frentes de las columnas, los Cuatro Evangelistas. Sobre ello y en la calle central: Resurrección y Ascensión y en las laterales, Aparición de María con el Niño a Santo Domingo y San Antonio, en la derecha, y San Vicente Ferrer y otro franciscano (quizás San Bernardino). Aun en las entre calles y en tamaño que vuelve a ser muy pequeño, los Cuatro Padres de la Iglesia latina, San Juan Bautista y San Cristóbal.

${ }^{27}$ Este fue también estudiado y reproducido en la comunicación al Congreso de Granada del año 73 y por ello puede revisarse en la publicación ya citada.
} 


\section{Aproximación al estilo de las pinturas}

Lo primero que tenemos que considerar es que tan sólo conocemos obra firmada del artista que abarca un breve periodo de tiempo, de 1593 a 1607 y que, basándonos en ella, hemos ido atribuyendo el resto de lo que, hasta ahora, consideramos su producción. Pero no cabe duda de que antes y después de esos tres escasos lustros, situados, eso si, en el centro de su larga existencia, hubieron otros muchos años de actividad, primero en su ciudad natal y luego ya en Roma, de la que no ha quedado huella documentada que nos permita saber si hubo evolución en su forma de expresión artística o si, por el contrario, esta que conocemos es su más definida personalidad estética. Lo más probable es que en esos veinte años anteriores al 93 y en los treinta posteriores al 07, se pueda ver alguna variación de estilo que nos permitiera buscar con mayor registro y por ello facilitara el hallazgo de firmas, siempre tan minúsculas que necesitan de potentes lentes de aumento, o también poder proponer más atribuciones, más o menos certeras. Aun así, por lo que ahora conocemos, se nos queda bastante bien definido al menos en ese periodo central de su vida productiva, tanto en composición, como figuras componentes, tipos humanos y colores.

Todo lo que conocemos es de asunto religioso, nada profano, de género o mitológico. Quizás tampoco lo hubo y se dedicó especialmente a los temas devotos que apunta Baglione. Igualmente y por la misma fuente, sabemos de su profunda religiosidad que, sin duda emana de los rostros de sus personajes y que al final de su larga vida, le llevó a entregarse de lleno a sus devociones.

Quizás sería justo destacar en este artista una fecunda riqueza inventiva que le hace usar poco el grabado y si lo hace, es como inspiración y no como fuente directa. Conocemos de él ya dos Apostolados completos: el del segundo mueble analizado en el Monasterio del Sacramento (Fig. 10) y el del Museo de Asturias (Fig. 1). No cabe duda de que ambos son obra directa del pintor, sin embargo para ninguno, al menos que yo sepa, utiliza alguno de los repertorios que ya estaban acuñados por haber sido grabados 28 , ni tan siquiera repite sus modelos propios en uno y otro ya que comparando cada figura con su correspondiente en uno y otro conjunto son totalmente distintas. Ahora bien sus inconfundibles rasgos idealizadores de los rostros son iguales en unos y otros, lo mismo se puede decir de la monumentalidad y corporeidad con que son tratados todos, los profundos paisajes de lejanías azuladas y grandes árboles de montaña y sobre todo, el inconfundible uso del color en vestimentas y en los entornos de ambientación. Es cierto que el alargado canon de la obra de Oviedo se achaparra en la de Madrid, pero también lo es que el muy pequeño tamaño que habían de tener estos últimos, aconsejaría ese acortamiento para destacar el rostro y su expresión.

La excepción la supone la pintura de San Miguel venciendo al Diablo que copia con mucha fidelidad el grabado de S. Van Hoogstraten, realizado sobre el cuadro de Martín de Vos, con la sola diferencia en la figura del Diablo que en el cuadro del pintor flamenco está tratado como una bella sirena con alas de ángel que cruza los brazos sobre los senos desnudos y aquí es un joven con orejas de asno y cola de reptil (Fig. 11).

En las demás láminas no se ha visto una dependencia clara con ningún otro grabado o incluso, cuadro coetáneo o precedente. Tan sólo el cobre de la Última Cena, pero recordemos que este nos presentaba dudas para atribuirlo con toda seguridad al artista debido a su mayor dureza de factura. Aquí comprobamos que es igual al grabado de Johannes Sadeler I ${ }^{29}$, si bien en el cobre se

\footnotetext{
28 Recordemos que los cobres de San Pablo y S. Simón citados en el primer mueble y evidentemente de otra mano, seguían los modelos de Rafael, grabados por Raimondi.

29 Grabador. Bruselas, 1550- Venecia?, 1600. Documentado en 1572 en Amberes, activo en Frankfort hacia 1587, trabajó para la corte de Guillermo V de Baviera, en 1593 estaba en Venecia, donde parece ser que murió tras visitar otras ciudades italianas. Hollstein, Dutch and Flemish Echings Engravings and Woodcuts, T XXI, p 83, Amsterdam Menno Hertzberger, 1949.
} 


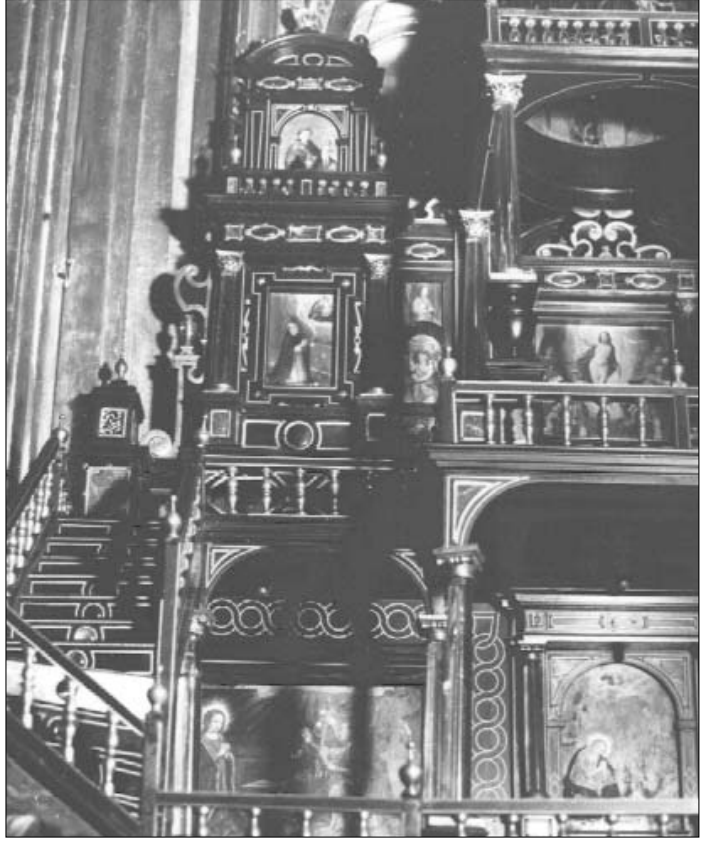

Figura 8. Mueble eucarístico y relicario. Detalle de la parte superior. Monasterio del Sacramento. Boadilla del Monte.

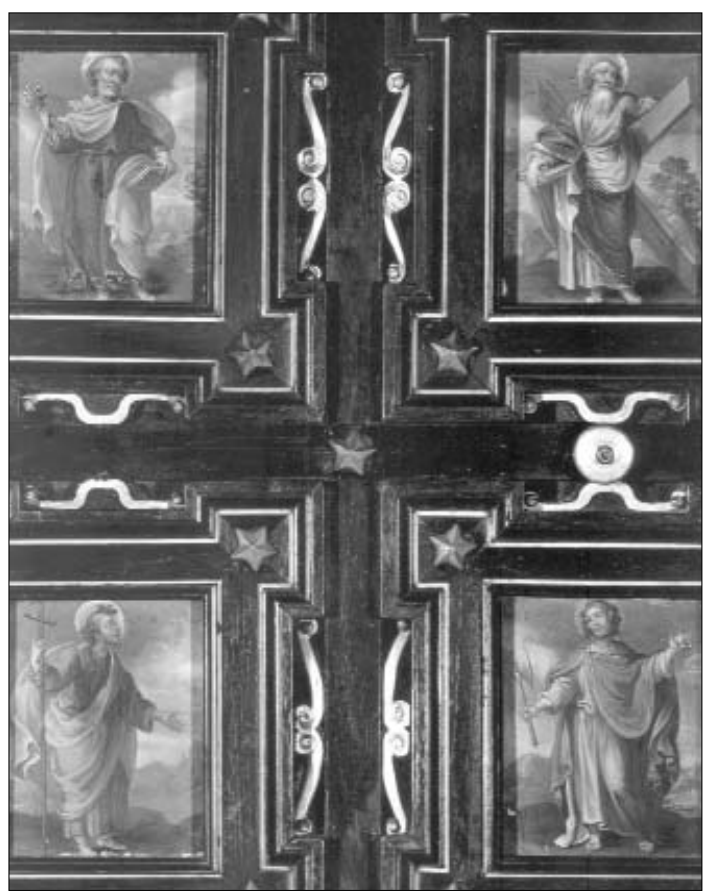

Figura 10. Detalle de Cuatro Apóstoles. Mueble eucarístico y relicario. Monasterio del Sacramento. Boadilla del Monte.

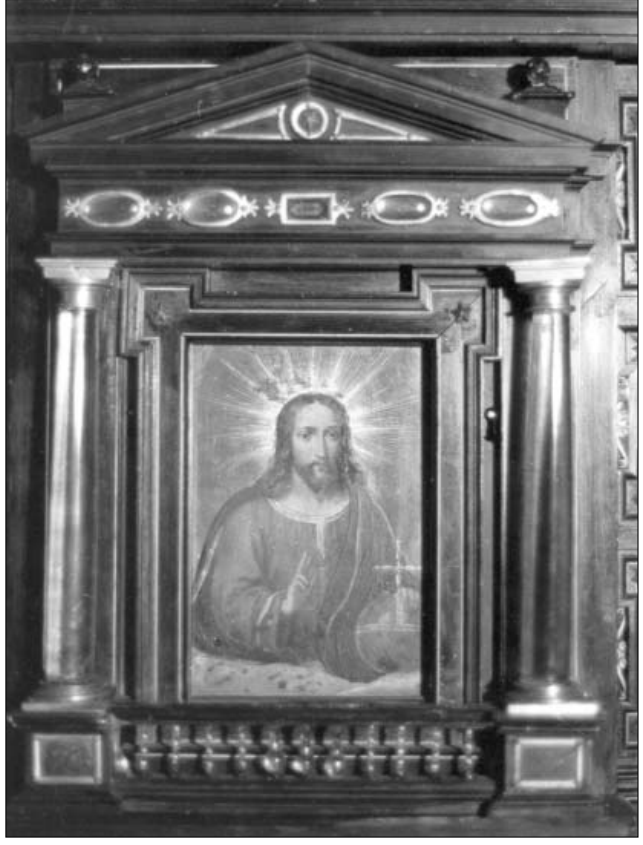

Figura 9. El Salvador. Detalle de la puerta del sagrario. Mueble eucarístico y relicario.

Monasterio del Sacramento. Boadilla del Monte.

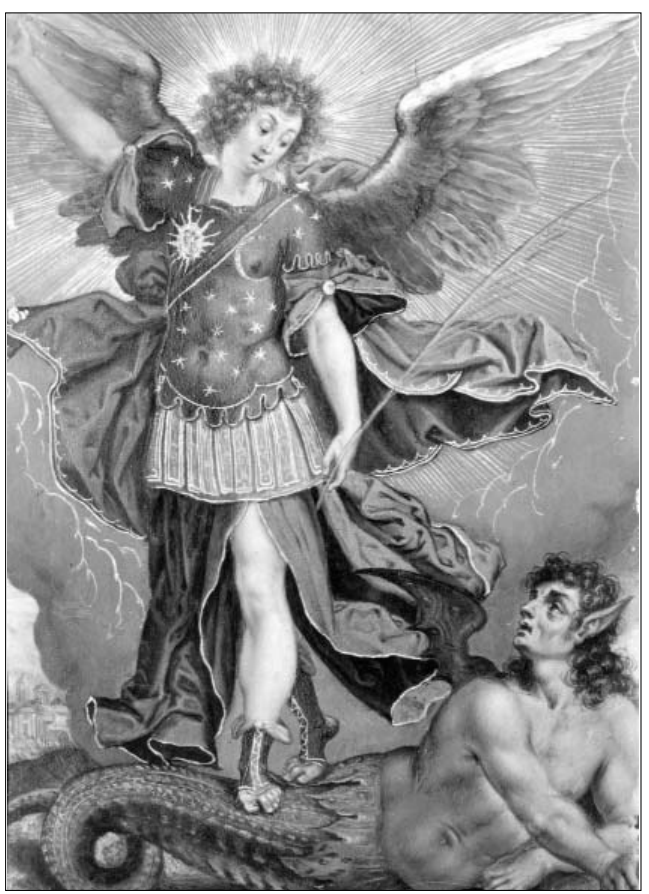

Figura 11. San Miguel venciendo al Diablo. Cara interior de las puertas del Armario. Monasterio del Sacramento. Boadilla del Monte. 
trata la escena en plano completo, viéndose la parte inferior de la mesa y apóstoles, perro y dos jarras, mientras el grabado está tratado en plano medio, esto es, solo desde el mantel de la mesa hacia arriba. De todas formas las fechas por las que se pintara y grabara este tema son tan coincidentes que quizás pudiéramos pensar en una fuente para ambos o incluso, en proceso inverso: que la pintura haya sido grabada ya que grabador, artista viajero, podía estar en Roma por esos momentos.

En todos los casos las figuras ocupan el primer plano, dejando tras ellos amplios paisajes o interiores arquitectónicos ambientados para la escena o con personajes secundarios. Esos paisajes los vemos espléndidos de detalle y color en caso de los Santos Penitentes: Juan Bautista (Fig. 12) y María Magdalena (Fig. 2), así como en San Francisco atendido por ángeles, si bien aquí irrumpe el rompimiento de Gloria desde lo alto. También detallado paisaje vemos en Santa Catalina, tratada como imagen icono, aunque una columna y una cortina cierren por lado izquierdo (Fig. 13). Las dos escenas de desposorios, tanto de Santa Inés (Fig. 14), como de Santa Catalina, tienen lugar entre nubes pobladas de ángeles que portan los símbolos de recompensa al martirio, o bien contemplan la escena. En esos cielos se consiguen muy variados matices de colores suaves, a veces con aspecto de pastel, con leves degradaciones de tonos, entre los cuales destacan vivamente los protagonistas de la acción que tienen igual corporeidad de las figuras aisladas y van vestidas con los tonos más vivos, enriquecidos con tornasoles y brillos metálicos de las ricas vestimentas y joyas, tan importantes en las pinturas de este artista que también, de seguro, se dedicaba a diseñarlas, así como a los suntuosos ornatos de bordado y brocado. Y los mismo recursos utilizó en las dos escenas desarrolladas en interiores: Arrepentimiento de San Pedro y Santa Cecilia en Oración. En la primera está el Apóstol en primer plano, con el gallo sobre pedestal detrás de él y al fondo, entre una estancia y otra, coloca a la criada que, ante el brasero, está informando a dos soldados. Tanto los referentes de arquitectura, como la iluminación de los distintos espacios están muy claramente definidos y sirven de perfecto marco al personaje principal. El cobre segundo representa a Santa Inés en oración ante el Crucificado mientras un ángel mancebo, de rodillas junto a ella, le va a colocar una corona de flores; están en una habitación de arquitectura ortogonal, aunque decorada con molduras y frisos con guirnaldas de roleos pintadas por las cornisas, y al fondo vemos el órgano con el que la Santa daba gloria a Dios (Fig. 15).

Estas mismas cualidades se aprecian en la Virgen del Séptimo Dolor que, con las mismas medidas que los cobres de las puertas, ocupa ahora un relicario aparte. El modelo se había ido creando a partir del siglo XIV y era de mucha devoción en las tierras de habla alemana, de donde procedía el pintor. Se representa con los colores habituales, rojo y azul, pero los forros del manto $\mathrm{y}$ virados de plegados, le proporciona la riqueza acostumbrada en todos los cobres. Se presenta sentada sobre unas piedras del paisaje con las siete espadas clavadas sobre el corazón. Dos ángeles de cuerpo entero, aunque de pequeño tamaño, están en oración ante ella y otras cinco cabecitas forman corona desde las nubes.

También una fuerte corporeidad y presencia imponente, al tiempo que muy rica gama de colores, encontramos en el Evangelista San Lucas, de colección particular madrileña. En un ámbito de tenues nubes azuladas, plateadas, rosadas y amarillentas destaca el primer plano del Santo, sentado sobre un paño rojo y escribiendo en libro que apoya sobre la cabeza del toro. Los ropajes son abundantes y forman amplios y profundos plegados en los que el color se intensifica, se mezcla o se degrada. La túnica es de amarillo intenso y el manto de azul ultramar, pero uno y otro se contrarrestan con el violeta de las vueltas y forros o las cenefas doradas que adornan los bordes de las ropajes con que viste a sus personajes.

Se preocupa asimismo de dotar a los personajes de acusada movilidad, buscando los suaves contrapostos o las leves torsiones de columna vertebral y huyendo del gesto demasiado explícito. Las posturas de los apóstoles del Apostolado de Oviedo están diseñados con gran elegancia dentro de su indudable monumentalidad y buscando siempre actitudes acompasadas de brazos y piernas. Quizás en los del Sacramento, al ser de tamaño más pequeño y sus cuerpos más cortos, se 


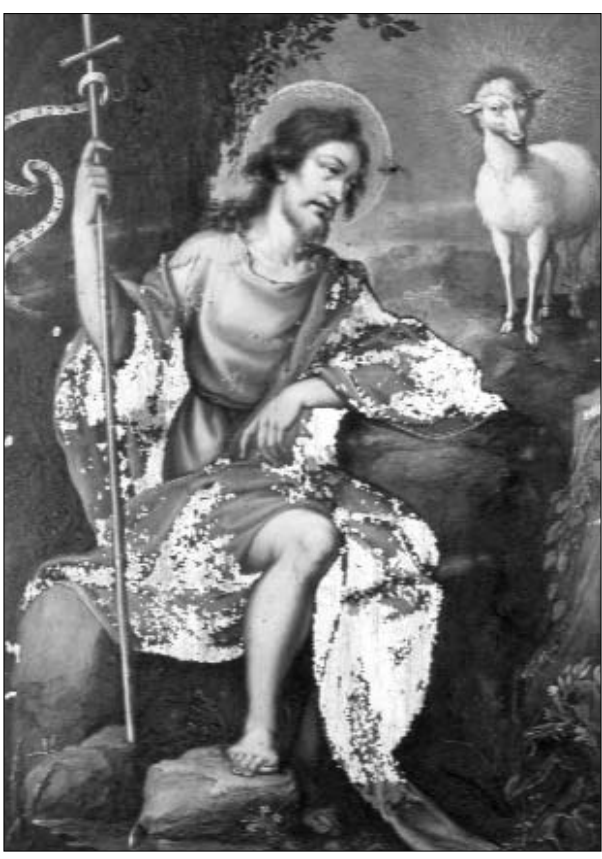

Figura 12. San Juan Bautista. Cara interior de las puertas del Armario. Monasterio del Sacramento. Boadilla del Monte.

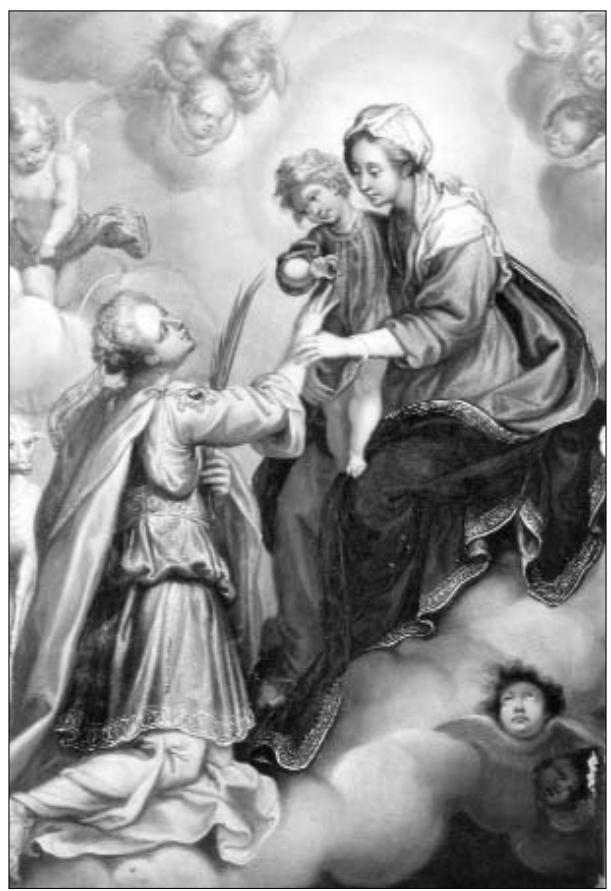

Figura 14. Desposorios místicos de Santa Inés. Cara interior de las puertas del Armario.

Monasterio del Sacramento. Boadilla del Monte.

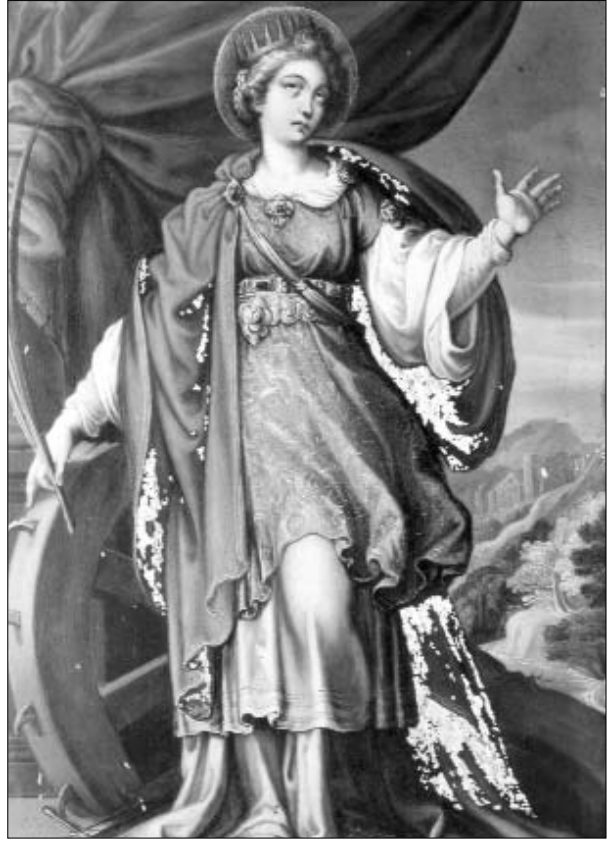

Figura 13. Santa Catalina. Cara interior de las puertas del Armario. Monasterio del Sacramento. Boadilla del Monte.

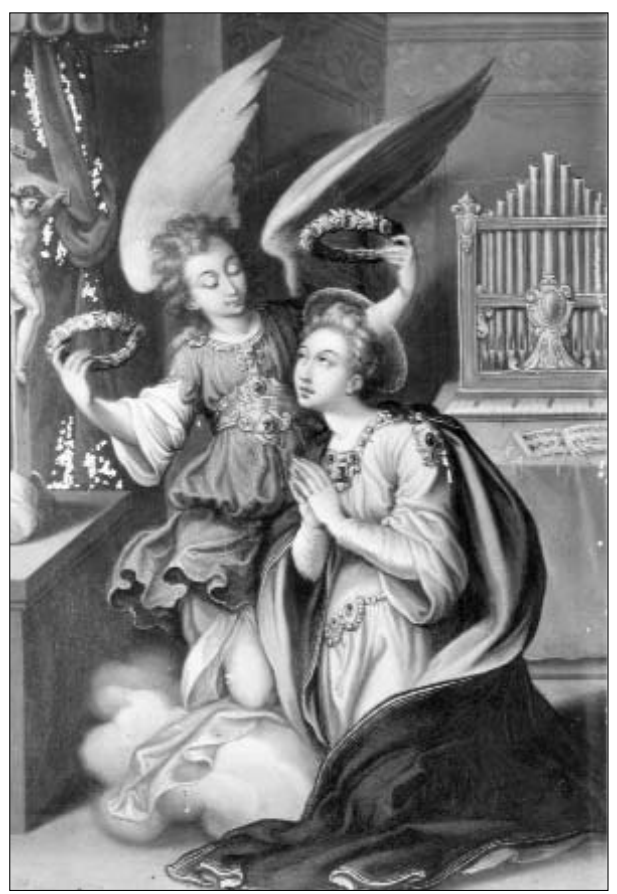

Figura 15. Santa Cecilia en oración. Cara interior de las puertas del Armario. Monasterio del Sacramento. Boadilla del Monte. 


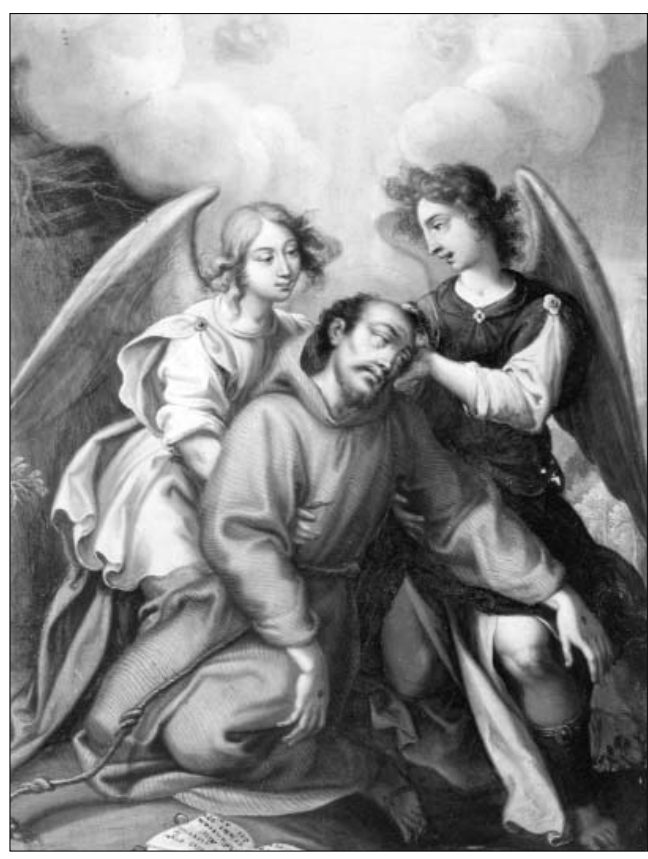

Figura 16. San Francisco auxiliado por ángeles. Cara interior de las puertas del Armario.

Monasterio del Sacramento. Boadilla del Monte.

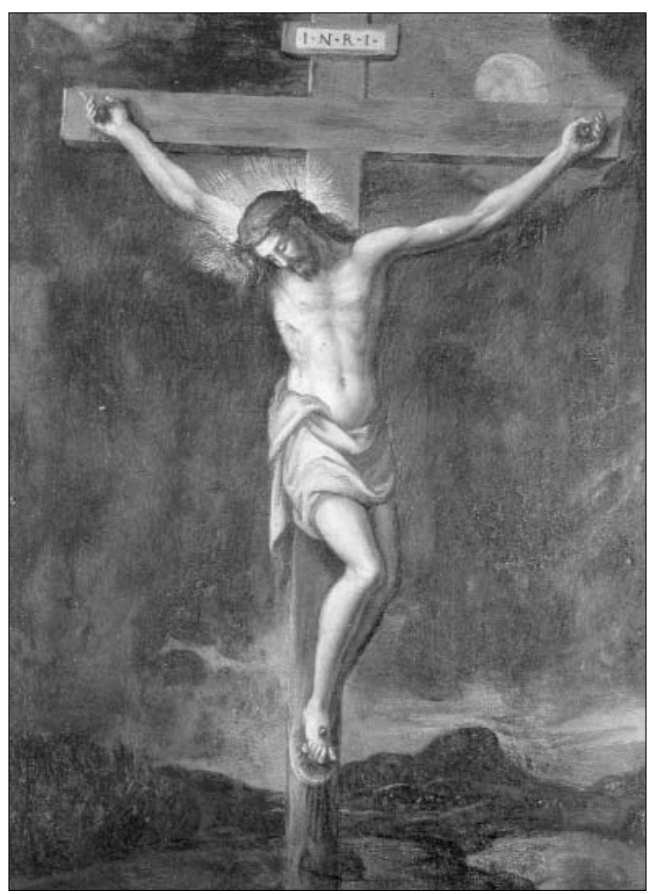

Figura 18. Crucificado. Retablito fingido que ocupa el fondo de la hornacina en el Armario. Monasterio del Sacramento. Boadilla del Monte.

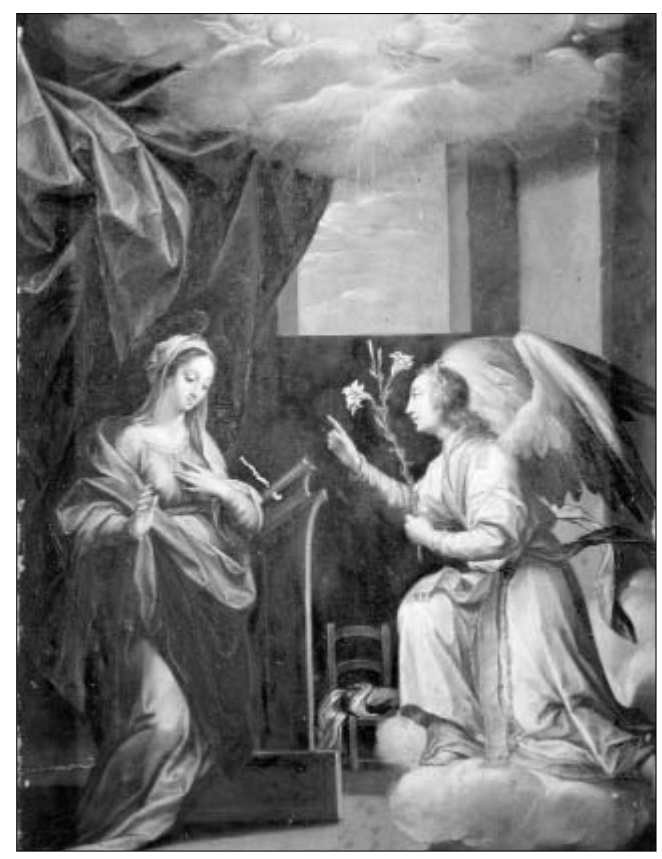

Figura 17. La Anunciación. Retablito fingido que ocupa el fondo de la hornacina en el Armario. Monasterio del Sacramento. Boadilla del Monte.

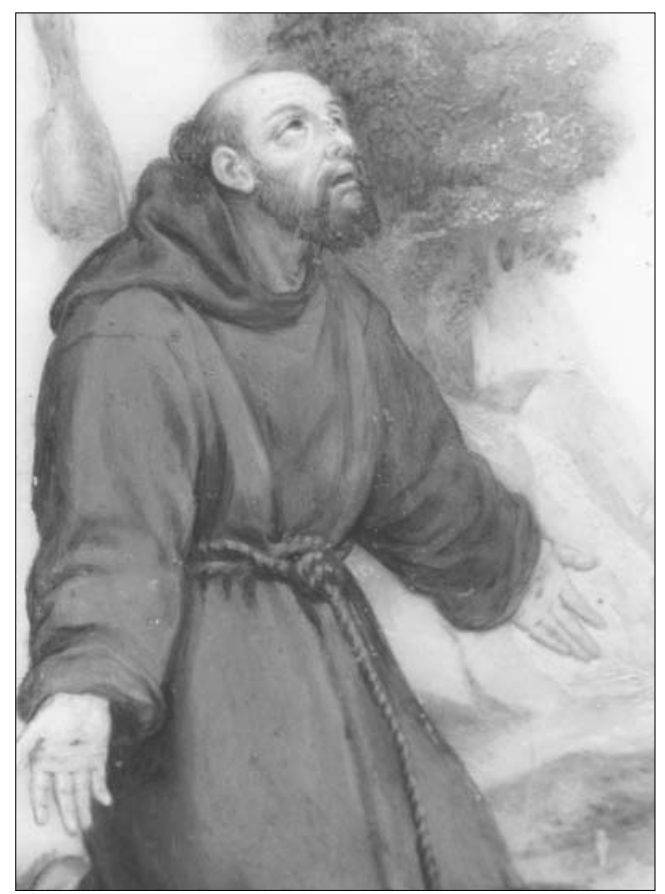

Figura 19. Estigmatización de San Francisco. Detalle. Iglesia de Santa María de la Estrella. Enciso. La Rioja. 


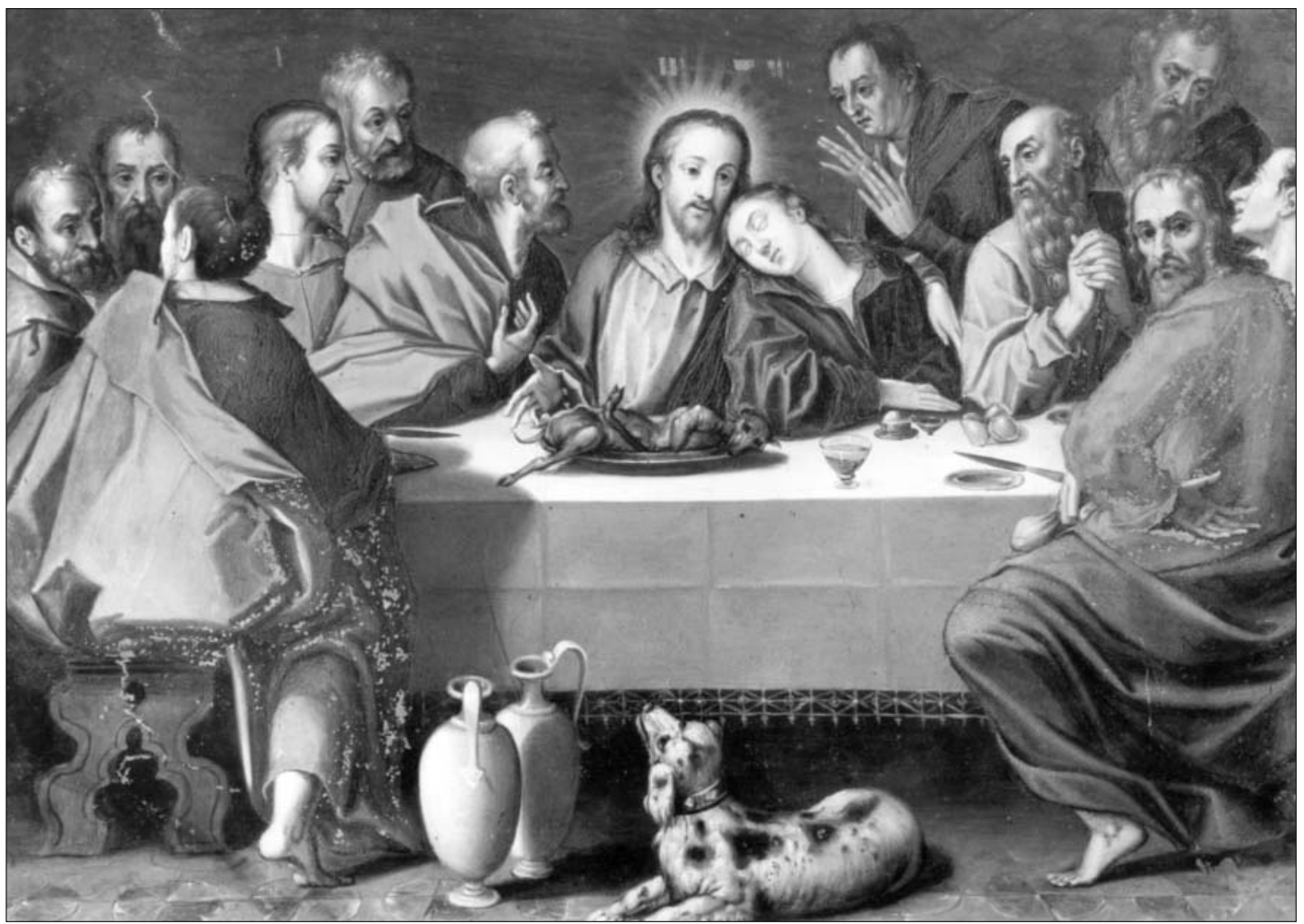

Figura 20. Última Cena. Armario. Monasterio del Sacramento. Boadilla del Monte.

define más el movimiento. Ese dulce contraposto, apenas perceptible pero muy sabiamente usado para animar la composición de la figura, lo vemos muy bien usado en el cobre de María Magdalena y en el de San Francisco auxiliado por ángeles (Fig. 16). Mas forzada es la postura del evangelista San Lucas que acabamos de citar en el párrafo anterior. Diríamos que hay incluso una búsqueda de inestabilidad que informe del lugar inmaterial en el que se encuentra escribiendo sus evangelios.

Los rostros son tan inconfundibles como los colores y sobre todo, la manera de conseguirlos sin que se pueda apreciar ninguna línea que defina, todo a base de suaves difuminados. Son rostros de rasgos finos en los que destacan unos ojos grandes y alargados, con mirada semicerrada o, por el contrario, dirigida al cielo que acusan su volumen ovoide en ambos párpados. Igual podemos decir del tratamiento anatómico, muy delicado, y las manos y pies, a veces con valientes escorzos, pero con la exquisita factura de las otras partes del cuerpo. Los cabellos y barbas son auténticas madejas de seda y abundan los tonos rubios en mujeres y ángeles, como corresponde a un artista centroeuropeo, formado con flamencos.

\section{Otras atribuciones}

Como antes se ha dicho, también la Anunciación, el Crucificado y La Oración del Huerto que centran el retablo simulado del armario del Sacramento se le pueden atribuir con bastante certeza. No de manera tan convincente la Última Cena que remata dicho mueble. En el primero todo 
es igual a los que forman el conjunto de las puertas y la Virgen, prácticamente idéntica a la que vemos en igual escena, en el relicario del Monasterio de la Encarnación. Sólo les diferencia un mayor aplomo en la composición de las figuras y de la escena (Fig. 17), pero eso ya vimos que puede deberse a la lógica evolución del artista al entrar en contacto con el mundo clasicista romano. Y en cuanto al Crucificado, cita muy de cerca al que el mismo artista pintó en el cobre de Santa Cecilia en oración, sólo que éste está ya muerto, aunque impregnado de gran serenidad. Muy curiosamente las letras que forman el I-N-R-I son de igual diseño en uno y en otro. El paisaje, de horizonte bajo, es como los que se pueden ver en los apóstoles, aunque aquí ha caído la oscuridad, acaecida tras la consumación del drama (Fig. 18).

Por último presentamos y reproducimos la lámina pintada sobre ágata, de la Parroquia de Santa María de la Estrella, en Enciso, La Rioja. Representa la Estigmatización de San Francisco 0’28 x 0’21 m., con el hermano León al fondo echado al suelo y una gloria de ángeles en el cielo (Fig. 4). Como siempre ocurría las vetas policromas y de perfiles concéntricos del ágata facilitaron la definición del paisaje rocoso en que se desarrolla la escena, si bien, por lo alto de las peladas rocas, aparecen los típicos ramajes y hierbas que utiliza Laire. El Santo en su actitud y sobre todo, las características faciales (Fig. 19), son en todo deudores de los tipos pintados por él. Y lo mismo podemos decir de las pequeñas cabecitas de ángeles que ocupan el ángulo superior derecho.

Recibido: 2-I-2006

Aceptado: 6-II-2006 